\title{
Combination of economic policies: how the perfect storm wrecked the Brazilian economic growth
}

\author{
Helder Ferreira de Mendonça ${ }^{1}$ (1) $\cdot$ Iven da Silva Valpassos ${ }^{1,2}$
}

Received: 19 March 2021 / Accepted: 3 November 2021 / Published online: 8 January 2022

(c) The Author(s), under exclusive licence to Springer-Verlag GmbH Germany, part of Springer Nature 2021

\begin{abstract}
This study uses a counterfactual analysis to investigate, from the Brazilian experience, the "perfect storm" resultant from the combination of economic policies on economic growth. Specifically, we analyze whether the combination of economic policies that neglect fiscal balance and low and stable inflation with the adoption of strategies to stimulate economic growth without considering the side effects on the economy harmed economic growth. Our findings, robust to several placebo tests, show Brazil's growth rate is approximately 2.8 pp below the "synthetic Brazil" growth rate. Furthermore, comprehending the great shocks in the period under investigation, the complementary empirical analysis supports the view that the "perfect storm" is the main factor explaining the underperformance of the Brazilian economic growth.
\end{abstract}

Keywords Economic policies · Economic growth $\cdot$ Emerging and developing countries

JEL Classification $\mathrm{O} 47 \cdot \mathrm{O} 23$

\section{Introduction}

Poor management of economic policy undermines economic growth. Undoubtedly, the policymaker's lack of commitment to fiscal balance and inflation control (economic policies type 1) leads to a deterioration of macroeconomic fundamentals. Moreover,

We would like to thank two anonymous referees, which have helped us improve the paper. Any remaining errors are the sole responsibility of the authors.

Helder Ferreira de Mendonça

helderfm@hotmail.com

1 Fluminense Federal University and National Council for Scientific and Technological Development, Department of Economics, Rua Royolze Carvalho de Mendonça, 88, Alto da Boa Vista, Miguel Pereira, Rio de Janeiro CEP: 26900-000, Brazil

2 Petrobras and Fluminense Federal University, Rio de Janeiro, Brazil 
policies in response to crises (economic policies type 2), if not applied correctly, can increase the economy's fragility and uncertainty. Thus, on the one hand, the government, through with price interventions, increases in the companies' market power, and mechanisms that hide a fiscal deterioration, tries to increase growth; on the other hand, such measures cause an increase in uncertainty and market failures that ends up reversing any benefit. In short, the combination of inappropriate economic policies (type 1 and type 2) results in a "perfect storm", leading to the need for austere policies to restore credibility, entailing a cost to economic growth that depends on how far the economy has deviated from what it would reach without the occurrence of the phenomenon.

This study uses a counterfactual analysis to investigate, from the Brazilian experience, the effect of a combination of economic policies on economic growth from 2011 to $2016 .{ }^{1}$ In other words, we compare the Brazilian economy's growth with the different emerging and developing economies that were not subject to the "perfect storm". 2 Although emerging and developing countries have similar economic characteristics, simultaneous episodes of economic policies type 1 and type 2 are not common in the period under consideration. Our analysis uses a comprehensive database of 88 emerging and developing economies from 1991 to 2018, corresponding to approximately 2500 observations.

We follow Abadie et al. $(2010,2015)$ framework to build a "synthetic Brazil" that provides a counterfactual of the growth rate corresponding to the weighted combination of countries that did not present cases of "perfect storm" in the period under analysis. The counterfactual makes it possible to compare the realized growth rate's path of the Brazilian economy with that we would see in the absence of the "perfect storm".

The adoption of inflation targeting implies that monetary policy's main objective is low and stable inflation and that fiscal policy must be prudent; governments must avoid high fiscal deficits (Mishkin 2000). The policymakers in Brazil combined the abandonment of inflation targeting with interventionist political actions aimed to promote growth. Therefore, it is essential to analyze the combined effect of these economic policies on economic growth.

In our analysis, the "perfect storm" phenomenon happens exclusively in Brazil (the country under treatment); thus, the other countries in the sample represent our control group. Using the synthetic control method, we evaluate how much the "perfect storm" affected the Brazilian economy's growth. In other words, we built a "synthetic Brazil": a comparable unit that consists of the weighted combination of emerging and developing economies that did not have the phenomenon during the treatment period and that presented similar growth paths for the period before treatment.

There are several advantages to using the synthetic control method to assess the "perfect storm" effect on economic growth. First, the difference between the treated unit (Brazil) and the control group (emerging and developing countries) is not constant over time. Therefore, the use, for example, of a "differences-in-differences" model is

\footnotetext{
1 The combination of inappropriate economic policies hereafter as "perfect storm".

2 The emerging and developing economies classification follows the International Monetary Fund (World Economic Outlook).
} 
not valid due to the violation of the "parallel trend" hypothesis. Second, the synthetic control method is based on counterfactuals. Therefore, it is not subject to the problems in econometric models. Third, in the "perfect storm", there is an inseparable relationship between the economic and political phenomena. For this reason, the extraction of empirical evidence from models that consider both effects in one regression can generate spurious results. Finally, an additional advantage of synthetic control models is that we use a set of variables to construct an artificial path for the variable of interest. In other words, we make a comparison between the real and synthetic trajectories without the need to identify the impact of a particular variable. Therefore, synthetic control permits one to consider the combination of economic and political effects on economic growth. In addition, synthetic control allows a comparison between Brazil's growth path with that of other countries, while traditional models do not allow this direct comparison. In summary, the comparison with the other countries in the sample permits us to assess whether the drop in the Brazilian growth occurred due to external factors that also affected the other emerging and developing economies, such as the Great Recession of 2008-2009, or whether it was due to internal factors.

The main result shows that Brazil's growth rate is approximately 2.8 pp below the "synthetic Brazil" growth rate. This result is significant because the emerging and developing countries have adopted several measures to recover their economies in response to the Great Recession of 2008-2009 and, on average, managed to smooth the fall in growth trajectories after two years of the event. It is noteworthy that Brazil's growth path is similar to the emerging and developing countries' average until 2010. However, after 2010, Brazil's economic growth fell more than the average of other countries, reaching a peak in 2015. In short, there is evidence that the occurrence of the "perfect storm" in Brazil led to a worsening of the growth rate when compared to that of other economies with similar income patterns. The result of the synthetic control method indicates that the absence of the "perfect storm" is consistent with an average growth from 2011 to 2018 of approximately $2.74 \%$, while the emerging and developing countries showed an average growth of $4.14 \%$. With the "perfect storm", Brazil's average growth (2011-2018) was only $0.65 \%$. The placebo test results confirm that Brazilian's growth rate drop is due to the "perfect storm". To give robustness to our results, we consider a set of donors that have a root mean square prediction error between the growth rate and the synthetic growth rate closest to the Brazilian case. ${ }^{3}$ Finally, we present the synthetic result from different country samples (emerging and developing, upper-middle-income, and countries with atypical performance regarding critical economic policies). It is noteworthy that because we are using annual frequency data for the period 1991-2018, the methodology used in this study is not subject to the problems pointed out by Carvalho et al. (2018) related to high-frequency data. ${ }^{4}$

Other relevant factors may explain the lower growth rate when Brazil's economic growth was under the "perfect storm" effect (2011-2018). Specifically, the impact of the Great Recession of 2008-2009 and President Dilma Rousseff's impeachment can be significant. To investigate whether the Great Recession and the impeachment are

\footnotetext{
3 In the same strand of Abadie et al. (2010), we use as a criterion the donors that have a difference less than or equal to twice the root mean square prediction error between the growth rate and the synthetic.

4 As an example of and application of the ArCo method proposed by Carvalho et al. (2018) for the Brazilian case related to interventions in the foreign exchange market, see Chamon et al. (2017).
} 
the only factors that slow Brazil's economic growth, we conduct a complementary analysis based on the Brazilian quarterly data from 2004 to 2018. The time series analysis demonstrates that the "perfect storm" effect is significant even when we explicitly consider the other factors that may have reduced the Brazilian economic growth in the period.

Recent literature recognizes the importance of fiscal policy on economic growth (Arin et al. 2019; Attinasi and Klemm 2016). In particular, there is evidence that high levels of public debt are associated with low growth. Conversely, a low level of public debt allows the fiscal policy to be more responsive to crises (Baharumshah et al. 2017; Stone 2016). Moreover, governments committed to sound fiscal policy management have higher economic growth (McManus and Ozkan 2015). Regarding monetary policy, most studies show that it has a relevant role in supporting economic growth (Twinoburyo and Odhiambo 2018). Since the 1990s, inflation targeting and central bank transparency have been a monetary policy benchmark to search for low and stable inflation (Samarina et al. 2014; de Mendonça and Guimarães e Souza 2012). Most of the literature shows that inflation under control and well-anchored inflation expectations creates a favorable environment for growth (Wong and Chong 2019; de Guimarães e Souza et al. 2016; Hartmann and Roestel 2013; Abo-Zaid and Tuzemen 2012; Mollick et al. 2011). Monetary policy in several countries changed after the Great Recession of 2008-2009. However, it is noteworthy that the aim of what became known as "unconventional monetary policies" was to stabilize the economy and not a strategy to promote long-term economic growth (Lombardi et al. 2018) ${ }^{5}$

Given that economic policies misapplication can damage economic growth, recently some researchers have analyzed several issues: the relevance of an increase in bank's credit to stimulate growth; the influence of popular support in adopting economic policies that prove to be wrong in the long-term; and the effect of bad governance over long-term growth; are some examples. Based on an analysis of the Chinese case regarding the increase in bank credit to fight the Great Recession of 2008-2009, Xue et al. (2020) find the limited positive impact of this strategy. Bó et al. (2018), supported by a model that considers the populist relationship between voters and policymakers, show that voters can support policies that will be bad in the long run but are seemingly advantageous to them in the short term. Finally, Tarek and Ahmed (2017) find evidence that poor institutional governance negatively affects economic growth, using a sample of seventeen countries in the MENA region.

Our work differs from the existing literature in several aspects. Firstly, as far as we know, our work is the first to analyze whether the "perfect storm" leads to a persistent economic growth reduction. Secondly, our methodological approach has the advantage of considering both effects of an economic and political nature without the need to analyze them separately as made in traditional models. Lastly, comparing the Brazilian economic growth performance with that of 87 other emerging and developing economies makes us possible to analyze whether the "perfect storm" was responsible for a distortion that led to lower growth in contrast to other countries.

\footnotetext{
5 For a review of the literature regarding the use of unconventional monetary policies, see Lombardi et al. (2018).
} 
This article proceeds as follows. Section 2 describes the type 1 and type 2 economic policies and shows how they characterize Brazil's "perfect storm". Section 3 presents the synthetic control method and the data used to estimate the "perfect storm" effect on economic growth. In Sect. 4, we present the estimation results of the "perfect storm" on growth and the placebo tests, as well as the robustness analysis. Section 5 provides a complementary empirical study, where we use time series to verify whether the lower Brazilian economic growth would be associated only with the Great Recession of 2008-2009 and President Dilma Rousseff's impeachment and not with the "perfect storm". Finally, Sect. 6 concludes.

\section{Brazil's "perfect storm"}

The perfect storm in this study corresponds to the occurrence, at the same time, of type 1 and type 2 economic policies. There is evidence that Brazil had a "perfect storm" from 2011 to 2014. Concerning type 1 economic policies, we precisely consider measures related to monetary and fiscal aspects and financial openness that did not consider the country's economic fundamentals. In other words, there was a deviation from the macroeconomic framework established in Brazil in 1999, which combines inflation targeting, search for fiscal balance, and a floating exchange rate. Concerning type 2 economic policies, our focus is on the economic measures that sought to increase economic growth through artificial control over prices, increases in the large companies' market power, and hiding fiscal deterioration. Although these measures might have a policymaker's "good intention" for increasing the gross domestic product, they created an environment of instability and market failures that reduced economic growth.

In order to identify the occurrence of type 1 and type 2 economic policies in Brazil from 2011 to 2014, we surveyed the main measures adopted by the Brazilian government and which were publicized through official communication channels of federal government agencies and news agencies (for example, Brazilian Legislation portal, Central Bank of Brazil, Regulatory Agencies, and Valor Econômico). ${ }^{6}$ After identifying the type 1 and type 2 economic policies, we made a qualitative assessment categorized into groups. ${ }^{7}$

In the case of type 1 economic policies, we consider four groups:

Type 1.a-Expansion of consumer credit to stimulate growth. As was evident from the Great Recession of 2008-2009, this economic policy strategy is careless if used persistently because the more households borrow, the more vulnerable the economy becomes. In brief, households' continued appetite for credit increases the risk that they will not repay their loans, which, therefore, increases the economy's instability. For example, on June 12, 2013, through provisional measure 620, the Federal Government of Brazil (FGB) authorized a US\$3.7 billion credit from the National Treasury to Caixa Econômica Federal (a public bank) directed to the financing of durable consumption.

\footnotetext{
6 Valor Econômico is the largest financial newspaper in Brazil.

7 The complete list of type 1 and type 2 economic policies in Brazil from 2011 to 2014 is available in Table A.1 (appendix).
} 
Type 1.b-Changes in the monetary policy interest rate without considering the economic fundamentals. According to the Brazilian inflation targeting regime adopted in June 1999, the monetary policy interest rate setting should consider Taylor's rule principle (Bogdanski et al. 2000). In short, if the inflation rate is above (below) the target, or if the growth rate is above (below) the potential growth rate, the result would be an increase (decrease) in the interest rate. Therefore, setting the interest rate without considering the inflation and output behavior would be incompatible with the inflation targeting system. For example, in 2012, the CBB's Monetary Policy Committee (COPOM) reduced the interest rate in six meetings (see COPOM decisions of 1/18/2012,3/7/2012,4/18/2012,5/30/2012,07/11/2012, and 08/29/2012), even with inflation expectations pointing to rates above the target established by the National Monetary Council.

Type 1.c-Uncertainty about the degree of financial openness in the economy. Due to increased exchange rate volatility, erratic decisions regarding the economy's openness may diminish the country's attractiveness for foreign investors. An example of the inconsistency of FGB's decisions is 2011. In practice, there were six interventions in capital flows through changes in the Tax on Financial Operations (IOF), and these changes were contradictory in some situations. For example, on 01/01/2011, the IOF to purchase investment fund shares by non-residents decreased from 6 to $2 \%$. However, on the same day, there was an increase in the IOF from zero to $2 \%$ in operations involving stock receipts issued outside Brazil (IMF 2011).

Type 1.d-Increase in fiscal risk arising from reduced taxes and increased current government spending. Attempting to recover the economy through policies to stimulate aggregate demand by lowering taxes and increasing government consumption may weaken the economy due to the increased debt/GDP ratio. For example, in 2014, the FGB reduced the primary surplus target by US\$ 43 billion (Law 13.053 of 12/15/2014) to accommodate the increase in current expenditures.

Regarding the type 2 economic policies, we consider three groups:

Type 2.a-Government's intervention in the prices of energy and fuels. The government's strategy of freezing energy and fuel prices for consumers raises an eventually future problem for the economy. When companies are allowed to readjust prices, the economy's impact can be so high that there is a risk of losing control over inflation. Moreover, the financial asphyxiation that energy companies are subjected to leads to a drop in profitability, leading to the need for public resources to remain viable. An example of this situation occurred in 2012. On 06/22/2012, through Decree 7764, the Brazilian government zeroed the tax on fuel sales (CIDE) to neutralize the price increase announced by Petrobras. ${ }^{8}$ Furthermore, on 9/14/2012, through decree 7805 , the government anticipated the renewal of electricity distribution contracts on the condition that concessionaires reduce energy prices.

Type 2.b-Reduction in market competition. Adopting measures that lead to market failures by favoring some companies can be detrimental to the economy. In particular, increasing market power for some companies, besides preventing new companies from appearing and growing, can promote a decrease in innovation due to less competition.

\footnotetext{
8 The largest oil and gas company globally and the largest multinational company headquartered in Latin America.
} 


\begin{tabular}{l|c|c|c|c|c}
\cline { 3 - 6 } & \multicolumn{5}{c}{ Type 1 } \\
\cline { 3 - 6 } & \multicolumn{2}{c}{ Type 1.a } & Type 1.b & Type 1.c & Type 1.d \\
\hline \multirow{4}{*}{ Type 2 } & Type 2.a & 2012 & 2011,2012 & 2011,2012 & 2011,2014 \\
\cline { 2 - 6 } & Type 2.b & 2012,2013 & 2011,2012 & $\begin{array}{c}2011,2012, \\
2013\end{array}$ & 2011,2013 \\
\cline { 2 - 6 } & Type 2.c & 2012,2013 & 2011,2012 & $\begin{array}{c}2011,2012 \\
2013\end{array}$ & $\begin{array}{c}2011,2013, \\
2014\end{array}$ \\
\hline
\end{tabular}

Fig. 1 "Type 1-type 2" matrix". Note Classification of years regarding the occurrence of type 1 and type 2 economic policies based on Table A.1 (appendix)

An example of the market intervention happened in 2011 when the FGB implemented the Greater Brazil Program (or Brazil Maior program). Among the program's objectives was financing large Brazilian companies inserted in large production chains to make them competitive in the international market. This initiative created the "national champions" that reduced competition in the domestic market, and most of them did not become competitive internationally.

Type 2.c-Lack of fiscal transparency (fiscal gimmickry). Using mechanisms to hide a fiscal deterioration through "creative accounting" can jeopardize market confidence in government actions. An example of this practice occurred in 2012. The FGB, using resources from the National Treasury, capitalized the National Bank for Economic and Social Development (BNDES), the Bank of Brazil (Banco do Brasil), and the Caixa Econômica Federal to expand credit at subsidized rates. ${ }^{9}$ Although the issuance of bonds by the Treasury did not lead to an increase in the federal government's net debt, the cost of raising funds by the Treasury was higher than the interest rates practiced by public banks in granting credit. For example, on 4/3/2012, the FGB, through Provisional Measure 564, authorized the National Treasury to issue debt of US\$ 24.7 billion for the BNDES to grant loans of up to US\$ 124 billion.

Based on the categorization and identification of the main facts that correspond to the type 1 and type 2 economic policies, it is possible to verify the formation of the perfect storm between 2011 and 2014. For this purpose, we used a "type 1-type 2" matrix that shows the simultaneous occurrence of type 1 and type 2 economic policies over the four years under consideration. The "type 1-type $23 \times 4$ " matrix lines correspond to the groups of type 2 economic policies: type 2.a, type 2.b, and type 2.c, while the columns in the matrix represent the type 1 economic policies: type 1.a, type 1.b, type 1.c, and type 1.d. Hence, each cell in the matrix represents the combination of a type 1and a type 2 economic policy in a specific year. For example, cell "type 1-type 211 " shows the years where a combination of credit expansion to stimulate growth and government intervention in energy and fuel prices occurred. Figure 1 shows that, for every year, there is an interaction between groups of type 1 and type 2 economic

\footnotetext{
${ }^{9}$ Bank of Brazil or BB is the biggest financial institution in Brazil. Along with Caixa Economica Federal, BNDES, Banco da Amazônia, and Banco do Nordeste, it is one of five state-owned banks by the Brazilian government.
} 
policies. The years 2011 and 2012 are noteworthy because there is evidence of the simultaneous occurrence of type 1 and type 2 economic policies for almost all groups.

\section{Methodology and data}

In the social sciences, it is common to use control groups when the researcher's objective is to evaluate the impact of a specific phenomenon on a unit of interest (country, state, city, company, and others). Under this view, to analyze the effects of the "perfect storm" on Brazil's economic growth, we would choose countries similar to Brazil as control and observe the difference between the Brazilian growth's path and the control units' paths. However, some problems arise with this approach. Firstly, the choice of countries used as control units in the analysis is subject to subjective factors. Secondly, the estimation of the effects of the "perfect storm" is subject to uncertainties whose simple comparison with the control units would not reduce, given that nothing guarantees that the control units reproduce the trajectory that would be observed for Brazil in the absence of the "perfect storm". Alternatively, we could opt for the difference-in-differences (DiD) method and construct the counterfactual based on the unweighted average of the control variables' economic growth. However, the DiD method considers the rigid assumption that the phenomenon's effects ("perfect storm") are constant over time and that eventual macroeconomic shocks also affect Brazil and the control units.

The synthetic control method addresses the problems mentioned above by allowing a counterfactual construction based on the sample's weighting. The synthetic trajectory built for Brazil is the one that comes closest to the economic growth trajectory observed before the "perfect storm". Furthermore, the placebo tests simulate the "perfect storm" in the other countries in the sample and, therefore, allow the construction of test statistics that prove that the estimated effects of the "perfect storm" are not the result of chance or just of factors that affected other countries in the sample.

This study uses a synthetic control to analyze the "perfect storm" effect, which occurred between 2011 and 2014, on Brazil's economic growth from 2011 to 2018. For this purpose, we use panel data with annual frequency regarding the economic growth (annual GDP growth rate-measured at US\$2010 — obtained from the World Development Indicators) of 88 emerging and developing countries, according to the classification of the International Monetary Fund, including Brazil from 1991 to 2018. Therefore, the sample period gives us twenty years of pre-treatment data and eight years of post-intervention, sufficient to build a viable counterfactual and sufficient post-intervention time to assess the "perfect storm" effect.

Consider $J+1$ the number of emerging and developing countries in the sample, indexed by $j$, and consider that $j=1$ denotes Brazil, the "treated unit". The units in the sample are observed for periods $t=1,2, \ldots, T$, with the corresponding pre-treatment period $t=1,2, \ldots, T_{0}$ and post-treatment $t=T_{0}+1, T_{0}+2, \ldots, T$. Furthermore, consider $Y_{i t}^{I}$ as the growth rate of country $i$ in period $t$ exposed to the intervention (the "perfect storm") at time $T_{0}$, and $Y_{i t}^{N}$ as the unobserved growth rate that would have occurred in the absence of the "perfect storm". We assume that there is no "perfect 
storm" effect before $T_{0}$, that is, $Y_{i t}^{I}=Y_{i t}^{N}$. Therefore, the "perfect storm" effect on growth is given by $\alpha_{i t}=Y_{i t}^{I}-Y_{i t}^{N}$ in period $t>T_{0}$.

To obtain synthetic Brazilian economic growth, that is, the growth that we would observe in the absence of the "perfect storm", we assume that $Y_{i t}^{N}$ follows a model of factors similar to that presented by Abadie et al. (2010, 2015):

$$
Y_{i t}^{N}={ }_{t}+\beta_{t} X_{i}+\gamma_{t} Z_{i}+\varepsilon_{i t}
$$

where $\kappa_{t}$ is an unknown common factor with constant weights for all units; $\beta_{t}$ is a vector $(1 \times M)$ of unknown parameters; $X_{i}$ is a vector $(M \times 1)$ of observed covariates (not affected by the "perfect storm"); $\gamma_{t}$ is a vector $(1 \times K)$ of common factors not observed; $Z_{i}$ is a weight vector $(K \times 1)$ of unknown factors; and $\varepsilon_{i t}$ are unobservable idiosyncratic shocks with zero mean.

Synthetic Brazilian economic growth is constructed as a weighted average of the control countries $j=2, \ldots, J+1$ (donor pool) represented by a vector of weights $W=\left(w_{2}, w_{3}, w_{4}, \ldots, w_{J+1}\right)^{\mathrm{T}}$ with com $0 \leq w_{j} \leq 1$ and $\sum_{j=2}^{J+1} w_{j}=$ 1. The value of the result variable for each synthetic control indexed by $W$ is:

$$
\sum_{j=2}^{J+1} w_{j} Y_{j t}={ }_{t}+\beta_{t} \sum_{j=2}^{J+1} w_{j} X_{j}+\gamma_{t} \sum_{j=2}^{J+1} w_{j} Z_{j}+\sum_{j=2}^{J+1} w_{j} \varepsilon_{j t}
$$

Furthermore, we consider the existence of a vector $\left(w_{2}^{*}, \ldots, w_{J+1}^{*}\right)$ such that: $\sum_{j=2}^{J+1} w_{j}^{*} Y_{j 1}=Y_{11}, \sum_{j=2}^{J+1} w_{j}^{*} Y_{j 2}=Y_{12}, \ldots, \sum_{j=2}^{J+1} w_{j}^{*} Y_{j T_{0}}=Y_{1 T_{0}}$ and $\sum_{j=2}^{J+1} w_{j}^{*} X_{j}=X_{1}$.

To obtain the synthetic of Brazilian economic growth, we selected the weight vector $\left(W^{*}\right)$ that minimizes the difference between the characteristics of the pre-intervention treated unit and a synthetic control given by $X_{1}-X_{0} W^{10}$ :

$$
\operatorname{Min} \sum_{m=1}^{M} v_{m}\left(X_{1 m}-X_{0 m} W\right)^{2}
$$

subject to:

$$
w_{2}+\cdots+w_{J+1}=1 \text { and } w_{0} \geq 0 \forall j=2,3,4, \ldots, J+1,
$$

where $m=1, \ldots, k, v_{m}$ is a weight that reflects the relative importance when measuring the difference between $X_{1 m}$ and $X_{0} W . X_{1 m}$ is the value of the m-th variable for the treated unit (Brazil), and $X_{0}$ is a vector $1 \times J$ that contains the values of the $m$-th variable for the units in the donor pool (emerging and developing countries).

Suppose $Y_{j t}$ as the result of the economic growth of country $j$ at time $t$. Furthermore, consider that $Y_{1}$ is a vector $\left(T_{1} \times 1\right)$ that collects the economic growth values of the

$\overline{10}$ To calculate the synthetic control, we used the statistical package for Stata "Synth" (Abadie et al. 2011). 
treated unit (Brazil) after the intervention, that is, $Y_{1}=\left(Y_{1 T 0+1}, \ldots, Y_{1 T}\right)^{\mathrm{T}}$, and $Y_{0}$ is a matrix $\left(T_{1} \times J\right)$ where the column $j$ contains the result values after the intervention for the unit $j+1$. Hence, the synthetic control estimator of the "perfect storm" effect on the Brazilian economic growth $\left(\widehat{\alpha}_{1 t}\right)$ is given by the difference between the results after the intervention in the treated unit and the synthetic control, $Y_{1}-Y_{0} W^{*}$ :

$$
\hat{\alpha}_{1 t}=Y_{1 t}-\sum_{j=2}^{J+1} w_{j}^{*} Y_{j t}, \quad t \in\left\{T_{0}+1, \ldots, T\right\} .
$$

We test whether Brazil's economic growth effects are caused by the "perfect storm" or the result of factors that equally influenced the other countries in the sample. Specifically, we verified the treatment effect if imposed on each of the countries that form the donor unit pool. In other words, we generate a distribution of placebo effects in loco given by $=\widehat{\alpha}_{1 t}^{P L}\left\{\widehat{\alpha}_{j t}: j \neq 1\right\}$. Because we are interested in verifying the occurrence of falls in the growth rate greater than those observed for Brazil, the unilateral $p$-value for negative values is:

$$
p \text {-value }=\operatorname{Pr}\left(\hat{\alpha}_{1 t}^{P L} \leq \hat{\alpha}_{1 t}\right)
$$

Due to the possibility that the quality of synthetic control is low for many donor countries, we use a p-value that takes into account the mean quadratic error of prediction in the pre-treatment period $\left(R M S P E_{\text {pre }}\right)$. In short, to calculate the standardized $p$-value $\left(p\right.$-value ${ }^{S}$ ) we use the ratios between $\widehat{\alpha}_{1 t}^{P L} / \mathrm{RMSPE}_{\mathrm{pre}}$ and $\widehat{\alpha}_{1 t} / \mathrm{RMSPE}_{\mathrm{pre}}$, so that:

$$
p \text {-value }^{S}=\operatorname{Pr}\left(\frac{\hat{\alpha}_{1 t}^{P L}}{\mathrm{RMSPE}_{\mathrm{pre}}} \leq \frac{\hat{\alpha}_{1 t}}{\mathrm{RMSPE}_{\mathrm{pre}}}\right) .
$$

As key predictors, in addition to the annual GDP growth rate (measured in US\$2010), we use ${ }^{11}$ :

Investment-annual percentage share of gross fixed capital formation in GDP (Gross Capital Formation-\% of GDP) gathered from the World Development Indicators (WDI). This variable is a proxy for investment considered essential in economic growth models (see, for example, Hendry and Krolzig 2004; Hoover and Perez 2004; de Guimarães e Souza et al. 2016).

Industry share-percentage share of industry in GDP (Manufacture value added-\% of GDP) available from the WDI database. The degree of industrialization of countries is closely linked to their capacity to generate value and the economy's size (see Abadie et al. 2015).

Agriculture share (\% of GDP)—percentage share of agricultural activity in GDP (Agriculture value added-\% of GDP) extracted from WDI. Agriculture is an essential component in explaining economic growth in emerging and developing economies (see Tiffin and Irz 2006).

\footnotetext{
11 We used several other predictors for economic growth, but their inclusion did not substantially alter the results found, and we opted for the more parsimonious configuration.
} 
Population growth - annual (total) population growth rate (\% YoY) obtained from WDI. Alongside the investment, the population growth rate is another mandatory variable in growth models (see, for example, Barro2003; de Mendonça et al. 2016).

Financial openness - is the index for opening the capital account provided by Chinn and Ito (2006). From a theoretical perspective, financial openness in competitive and efficient markets increases economic growth due to improved capital allocation (Bussière and Fratzscher 2008).

Furthermore, we used the average from 1991 to 2010 for the first four predictors mentioned above and the average from 2000 to 2010 for financial opening. In addition, we added five lags to the economic growth rate (1991, 1995, 2000, 2005, and 2010).

\section{4 "Perfect storm" effect on growth}

Figure 2 shows Brazil's economic growth path and the average of the 87 emerging and developing countries representing the donor pool for the period under analysis (1991-2018). Although Brazil has a growth rate below the average of emerging and developing countries, the difference between the trajectories increases substantially after the "perfect storm". The difference between the Brazilian growth rate and that of the other emerging and developing countries was - 1.1 pp for the 1991-2010 period. However, for the 2011-2018 period, the difference became - 3.49 pp.

Suppose synthetic Brazil can reproduce the economic growth trajectory in the pretreatment period and reproduces the values of the key predictors. In that case, it is possible to say that the synthetic control unit can present the 2011-2018 growth path in the absence of the "perfect storm".

Figure 3 shows that in the period before the treatment ("perfect storm"), the Brazilian economic growth rate and its synthetic are very close (the average difference in

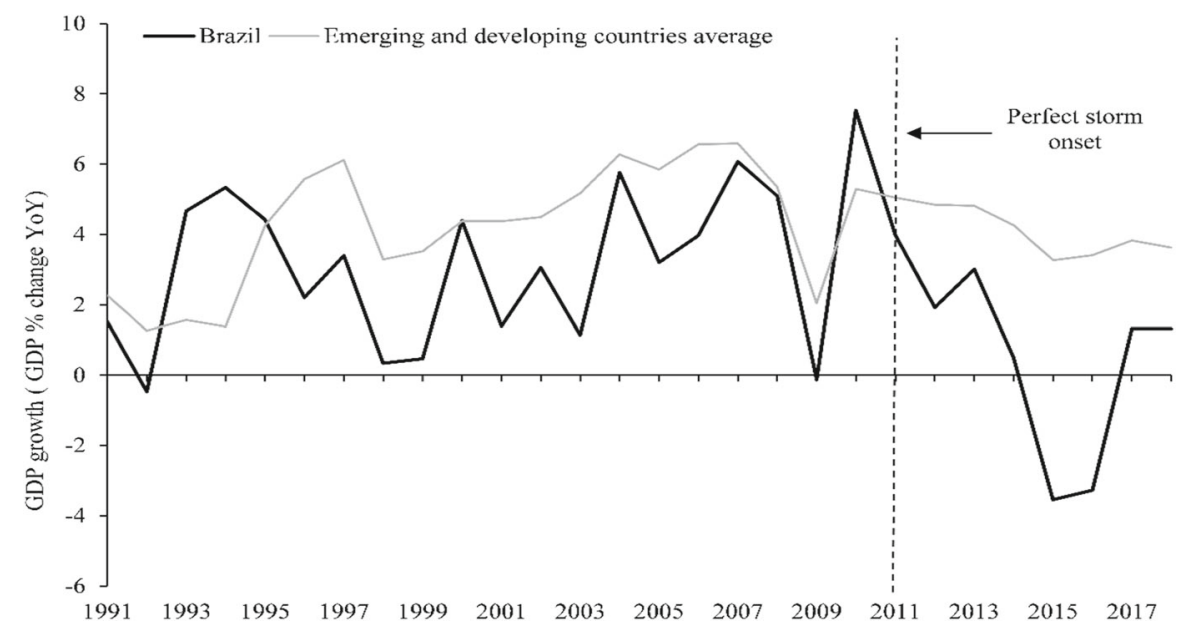

Fig. 2 Economic growth trajectory (1991-2018): Brazil versus the average of 87 donor countries 


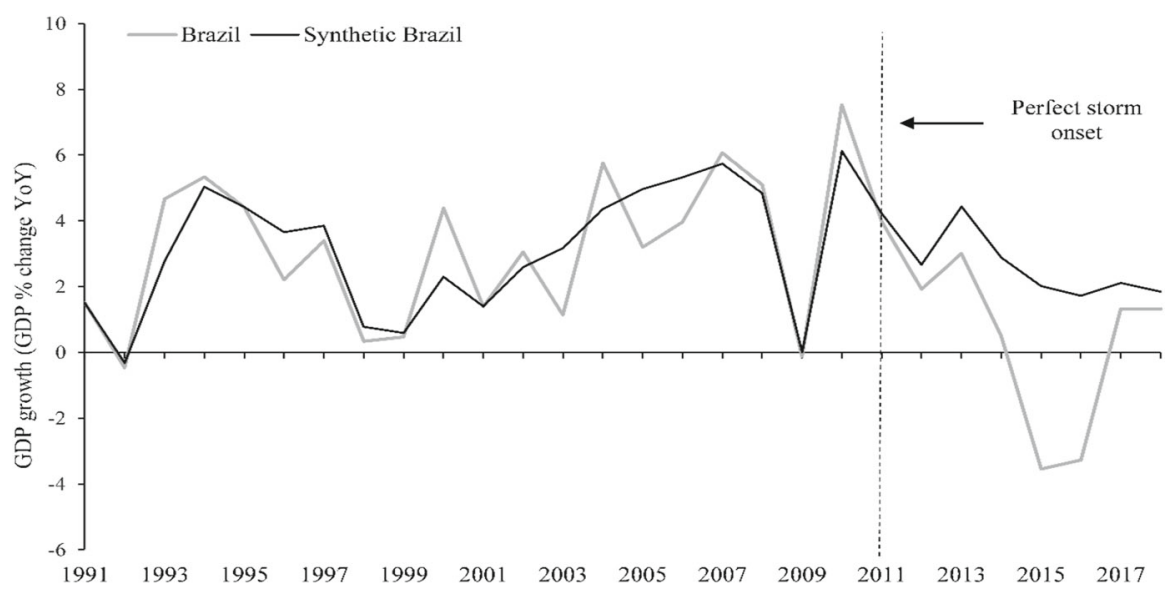

Fig. 3 Economic growth trajectory (1991-2018): Brazil versus synthetic Brazil

absolute terms is $0.04 \mathrm{pp}$ ). Furthermore, Table 1 compares the values of key predictors for Brazil before 2011 with the same values for synthetic Brazil and the average of 87 emerging and developing countries (donor pool). In general, the results in Table 1 suggest that synthetic Brazil provides a much better comparison for Brazil than the average for emerging and developing countries.

Anticipation effects can affect some predictor variables. For example, the anticipation of adverse economic conditions might have led to reduced private investment before the actual implementation of the policy if companies could envision that this would possibly dampen the prospective returns of investment projects. Regarding the

Table 1 Averages of predictors of economic growth before the "perfect storm"

\begin{tabular}{lccc}
\hline Predictors & Brazil & Synthetic Brazil & EDEV sample \\
\hline Investment & 18.87 & 19.05 & 22.98 \\
Industry share & 15.23 & 15.18 & 14.18 \\
Agriculture share & 5.30 & 9.86 & 18.09 \\
Population growth & 1.36 & 1.87 & 1.91 \\
Financial openness & -0.11 & 0.41 & 0.17 \\
GDP Growth (1991) & 1.51 & 1.51 & 2.26 \\
GDP Growth (1995) & 4.42 & 4.43 & 4.26 \\
GDP Growth (2000) & 4.39 & 2.49 & 4.26 \\
GDP Growth (2005) & 3.20 & 4.46 & 5.84 \\
GDP Growth (2010) & 7.53 & 7.20 & 5.29 \\
\hline All variables are averaged
\end{tabular}

All variables are averaged for the period 1991-2010, except the financial openness (Kaopen index, see Chinn and Ito 2006), which is averaged for the period 2000-2010. The last column shows the donor's pool average (87 emerging and developing economies—see Table A.1—appendix)

$E D E V$ emerging and developing economies 
Table 2 Weights of countries in synthetic Brazil

\begin{tabular}{llll}
\hline Country & Weights & Country & Weights \\
\hline Congo Republic & 0.054 & Mexico & 0.063 \\
Ethiopia & 0.036 & Paraguay & 0.270 \\
Gambia & 0.045 & Peru & 0.196 \\
Lebanon & 0.004 & South Africa & 0.333 \\
\hline
\end{tabular}

Based on the synthetic control method, extrapolation is not allowed, and thus all weights are between $0 \leq w_{j} \leq 1$ and $\sum_{j=2}^{J+1} w_{j}=1$. Table reports only countries with $w_{j}>0$

model, one consequence is that if the treatment period is inaccurate, the interpretation of the results can be misleading. Hence, to check if there is an "anticipation effect" or even a "repercussion effect" caused by the global financial crisis of 2008, we performed a new synthetic model changing the pre-treatment period for 1991-2009 and the post-intervention period for 2010-2018 (an "in-time placebo" test). The results (see Figure A.1-appendix) that there is no anticipation effect. We identify that after a higher economic growth in 2010, the rates started to decrease in 2011, the same year the "perfect storm" began.

The weighting of the predictors $\left(v_{m}\right)$ corresponds to ${ }^{12}$ : Investment $(0.303)$; Industry share (0.003); Agriculture share (0.028); Population growth (0.0001); Financial openness (0.003); and GDP Growth in 1991 (0.238), 1995 (0.355), 2000 (0.004), 2005 (0.007), and $2010(0.059)$. The $w_{j}$ weights reported in Table 2 show that the Brazilian economic growth rate is best reproduced by the combination of South Africa, Paraguay, Peru, Mexico, the Republic of Congo, Gambia, Ethiopia, and Lebanon. The other countries in the donor pool had weights equal to zero. It is reasonable that South Africa is the largest weight (0.333). Like Brazil, South Africa is an emerging country with characteristics that place it in the group of countries known as BRICS and, therefore, have similarities regarding economic growth. The second most important country is Paraguay, which is part of Mercosur and thus has close relations with Brazil in terms of trade. Moreover, Brazil has a history of major investments with Paraguay, such as Itaipu (one of the world's largest hydroelectric plants). Finally, it is worth noting that South Africa, together with the other three Latin American countries highlighted (Paraguay, Peru, and Mexico), represent $86 \%$ of synthetic Brazil.

Figure 4 shows the "perfect storm" effect on economic growth (distance between Brazil and synthetic Brazil). The occurrence of type 1 and type 2 economic policies from 2011 caused the fall in the economic growth rate to worsen from 2013. The fall in the growth rate is accentuated until its peak in 2015 when it reaches a reduction of $-5.6 \mathrm{pp}$. Although the "perfect storm" effect weakened in the 2017-2018 period,

\footnotetext{
12 The choice of $m$ is based on Abadie et al. (2010) so that the result of synthetic control has the best approximation for the pre-intervention trajectory of economic growth. Notwithstanding, because the set of weights $m$ is not country-specific in the synthetic control method, it can be inappropriate for each donor country. To check if each $m$ connected to the key predictors in Brazil's model is not an outlier, we performed the synthetic for each donor country to extract the $m$, and then we compared the result through box plots graphs (see Figure A.2-appendix). In general, the results do not show that Brazil's $m$ are outliers.
} 


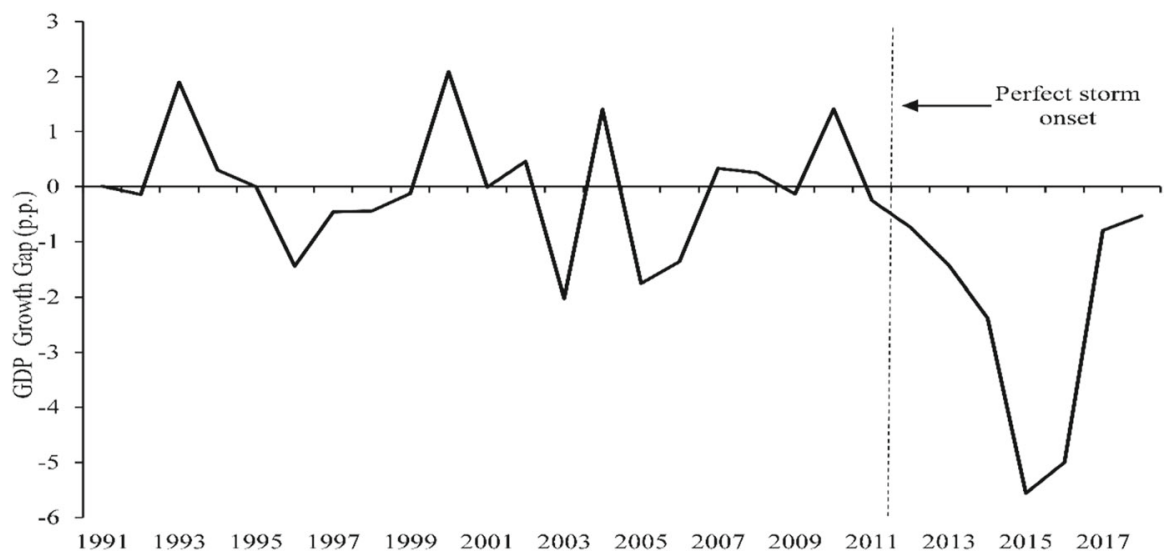

Fig. 4 "Perfect storm" effect on economic growth

the average effect on the economic growth rate for the entire post-treatment period is approximate $-2.08 \mathrm{pp}$.

\subsection{Placebo tests}

To validate the previous section results, we performed several placebo tests: "in-space", "leave-one-out", and use of a subsample of the donor pool. For the in-space test, the treatment is assigned in an iterative way to each donor country. From this procedure, it is possible to assess whether the "perfect storm" effect on Brazil's economic growth is substantial compared to the effects that would be perceived for countries that are part of the donor pool. In other words, if the estimated effects for donor countries are similar to those calculated for Brazil, the results could be explained by factors other than the "perfect storm".

Table 3 shows, for each year of the post-treatment period (2011-2018), the proportion of countries in the donor pool has a more significant negative effect on economic growth than Brazil. In order to avoid a possible bias in the test statistic ( $p$-value) due to the impossibility of finding a convex combination of countries that replicates the economic growth trajectory in the pre-treatment period, we consider the post-treatment effect in each country donor divided by the RMSPE of the pre-treatment period [see Eq. (6)]. Moreover, to verify that the results are robust, we repeat the "in-space" test considering only donor countries that have RMSPE with a magnitude up to twice Brazil's RMSPE in the pre-treatment period. Finally, to assess whether there is a real causal effect of the intervention, we analyzed the proportion of donor countries with a post-treatment RMSPE/pre-treatment RMSPE ratio greater than Brazil's. A low proportion of countries in the donor pool with a post-treatment RMSPE/pre-treatment RMSPE ratio is indicative of the causal effect of the "perfect storm" on growth.

Table 3 shows that from 2012 the negative effect of the "perfect storm" on Brazil's growth becomes more evident than the other countries. Furthermore, the low proportion of countries in the donor pool with a post-treatment RMSPE/pre-treatment 
Table 3 Placebo test—“in-space”

\begin{tabular}{lll}
\hline Year & $\begin{array}{l}\text { Proportion of sample with } \\
\text { effect on growth }>\text { Brazil's } \\
\text { effect (all donors) }\end{array}$ & $\begin{array}{l}\text { Proportion of sample with } \\
\text { effect on growth }>\text { Brazil's } \\
\text { effect (donors with RMSPE } \\
\leq 2 \times \text { RMSPE Brazil) }\end{array}$ \\
\hline 2011 & 0.37 & 0.54 \\
2012 & 0.11 & 0.09 \\
2013 & 0.07 & 0.09 \\
2014 & 0.01 & 0.00 \\
2015 & 0.00 & 0.00 \\
2016 & 0.00 & 0.00 \\
2017 & 0.01 & 0.00 \\
2018 & 0.01 & 0.03 \\
Proportion of donors with a & 0.01 & 0.03 \\
RMSPE & & \\
Number of donors & 87 & 35 \\
\hline
\end{tabular}

The $p$-value (one-tailed) for each year represent the proportion of countries for which the negative gap between observed GDP growth and synthetic GDP growth were greater (absolute value) than the gap between Brazil's observed and synthetic GDP growth. The gaps are normalized by the pre-treatment RMSPE (RMSPE $\mathrm{pre}_{\text {e }}$ of each donor. For instance, if the gap for country A is -1.5 and its RMSPE is 3 its standardized effect is equal to $-1.5 / 3$, that is, 0.5 . We conduct the "in-space" placebo test using the Stata package Synth Runner (Galiani and Quistorff 2017)

RMSPE ratio greater than Brazil indicates a large "perfect storm" effect on economic growth. The results are confirmed when we restrict the donor pool countries with RMSPE to two times greater than Brazil's RMSPE in the pre-treatment period.

Another way to present the "in-space" placebo test results is by comparing the trajectory of Brazil's effect [see Eq. (4)] with those observed in the donor pool countries. Panel A in Fig. 5 shows the case in which all the donor pool countries are considered, and panel B, the situation in which countries with RMSPE greater than twice Brazil are excluded. In both cases, it is clear that the effects of adopting type 1 and type 2 economic policies in Brazil have worsened economic growth compared to other countries. This analysis is particularly relevant because it shows that the "perfect storm" phenomenon happened only in the Brazilian economy. If had had a lagged effect of the GFC on Brazil, the result on the Brazilian economic growth (black line-Fig. 5) would be similar to the effect on the growth of the donor countries (gray lines-Fig. 5).

Because some donor countries can be affected by the Brazilian economic trajectory, there is a possibility of a bias in the measurement of the treatment, and its direction is not obvious. On the one hand, to the extent that these countries are trading partners of Brazil, they should be affected negatively by a downturn of the Brazilian economy. On the other hand, to the extent that the donors are competitors of Brazil in other markets, they might benefit from the reduced competitiveness of Brazil. Therefore, if the first (second) effect dominates, one would expect that the treatment effect is underestimated 


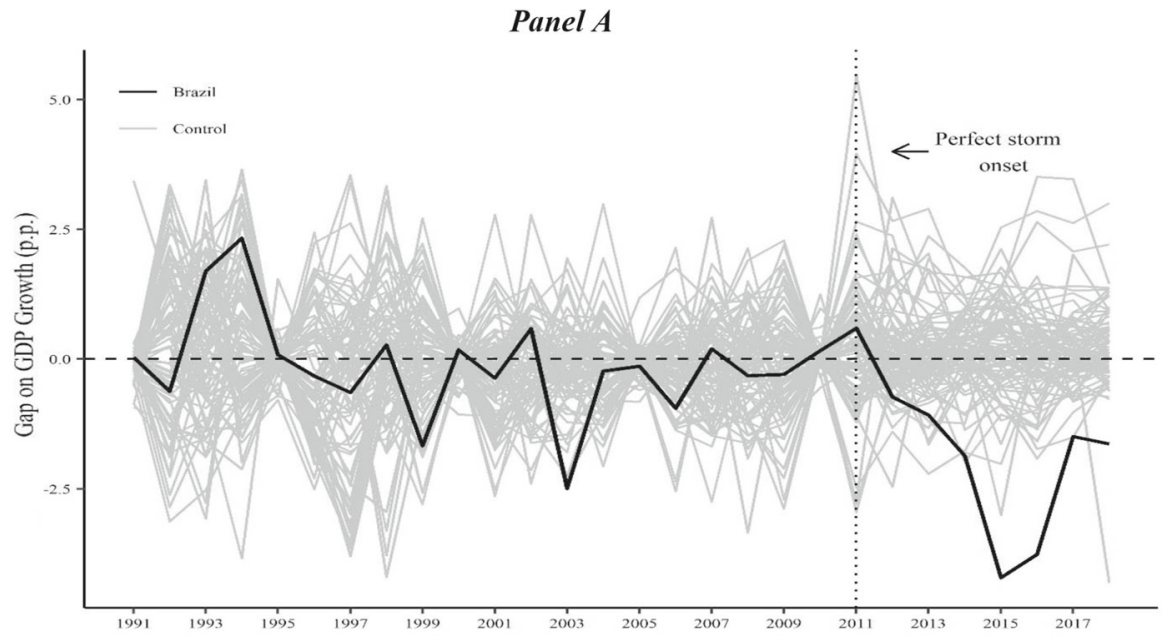

Panel B

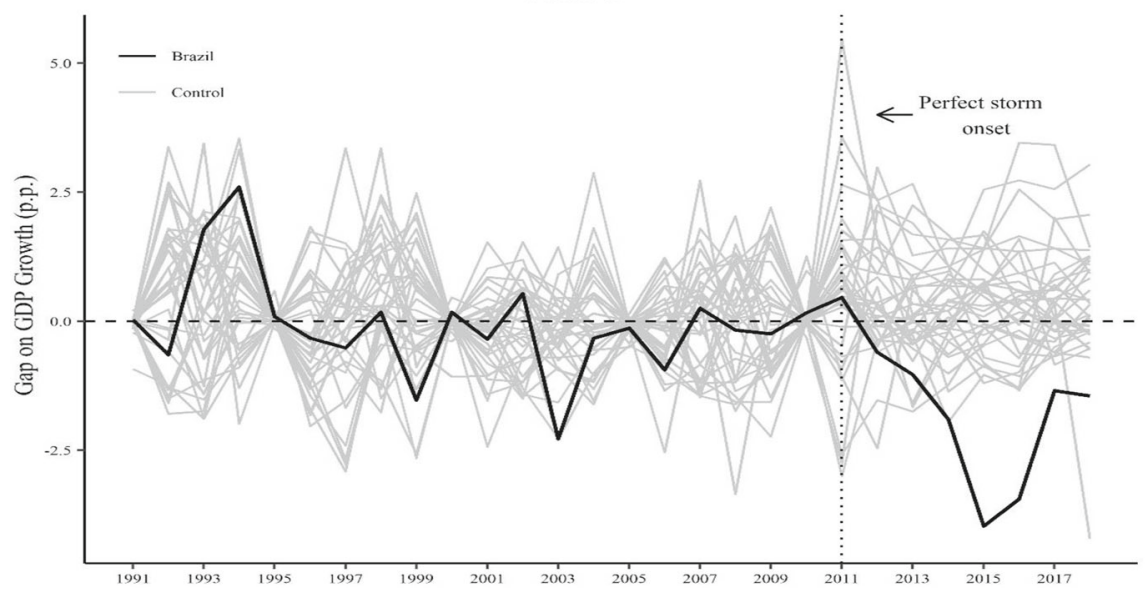

Fig. 5 In-space placebo test: effect on the Brazilian growth and placebo effect for control countries. Notes Panel A shows the "perfect storm" effect on growth in Brazil and the effect of placebo in all 87 control countries. Panel B shows the "perfect storm" effect on growth in Brazil and the effect of placebo in 35 control countries (countries with RMSPE up to twice Brazil's RMSPE in the pre-treatment period)

(overestimated). ${ }^{13}$ Hence, to assess whether the inclusion of a country in the donor pool causes some bias, we performed the "leave-one-out" test. In other words, we iteratively eliminate the eight countries in the donor pool with positive weights in synthetic Brazil (Congo Republic, Ethiopia, Gambia, Lebanon, Mexico, Paraguay, Peru, and South Africa) to assess whether the results are sensitive to eliminating one of the countries. In general, Fig. 6 shows that the results are robust to removing countries from the donor pool. The trajectory of synthetic Brazil is lower than that observed for the synthetics with the exclusion of countries. In brief, synthetic Brazil

\footnotetext{
13 We would like to thank one reviewer for this interpretation.
} 


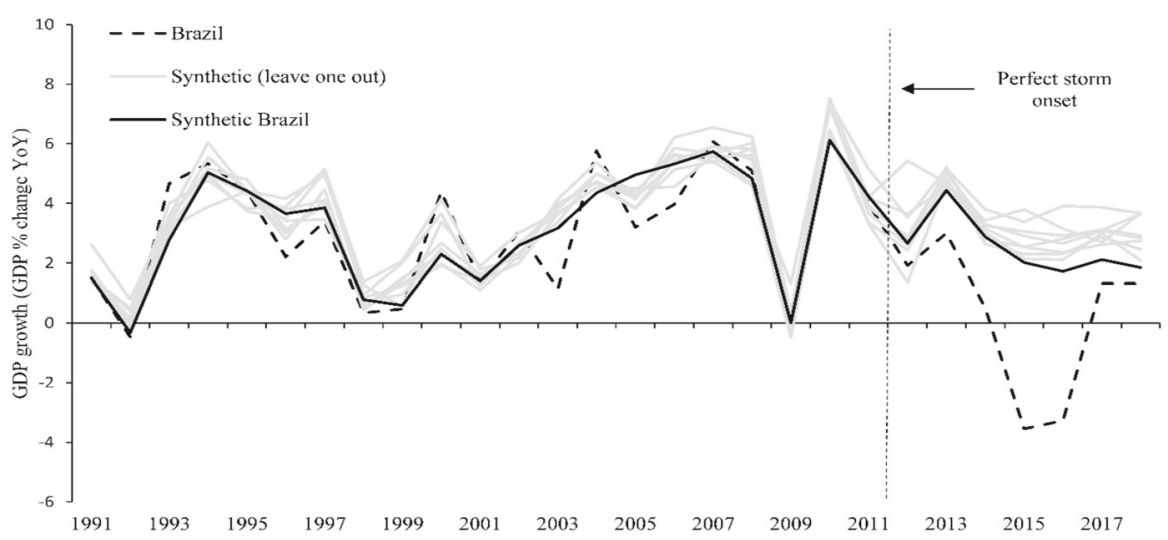

Fig. 6 "Leave-one-out" placebo test: distribution of synthetic control to Brazil

represents a conservative estimate of the intervention's effect ("perfect storm") on economic growth. Thus, there is no indication of a bias caused by the donor pool in the model.

As an additional robustness test, we built a counterfactual based on a subsample of 27 countries in the donor pool that considers only the countries with upper-middleincome (World Bank classification). Figure 7(panel A) shows that the result of the estimation of synthetic Brazil generated from the total sample of countries is very close to that resulting from the subsample of the countries with upper-middle-income (subsample 1). Regarding the "perfect storm" effect on economic growth (Fig. 7-panel B), the use of samples from different countries also did not change the results significantly. The trajectory of the effects shows that when considering the subsample of countries with upper-middle-income, the negative effect of the "perfect storm" on economic growth becomes slightly greater for the years 2015 and 2016.

One essential issue in our analysis is to show that the "perfect storm" is not the case of responses to the economic crisis but the combination of inappropriate economic policies. Concerned with this issue, besides the previous analysis considering the subsample of countries with upper-middle-income, we provide a placebo test based on a donor pool that comprehends the countries with atypical performance regarding crucial macroeconomic indicators. In short, we are considering the countries that put little emphasis on inflation control and fiscal consolidation. From the sample of 88 emerging and developing economies, we considered only countries with poor performance regarding relevant macroeconomic indicators. ${ }^{14}$ Specifically, we identify the countries for this donor pool (subsample 2) through those placed in the first and last decile regarding the yearly variation of the macroeconomic variables under analysis (see Table A.2). The synthetic path from the subsample and the trajectory of the effects are similar to those regarding synthetic Brazil's full sample (see Fig. 7). In

\footnotetext{
14 Inflation, public debt, financial openness, and credit to private sector. "Inflation" is the consumer prices (annual \%); "public debt" is the central government debt, total (\% of GDP); and "credit to private sector" is the domestic credit to private sector (\% of GDP); from the World Bank. "Financial openness" is the index for opening the capital account (Chinn and Ito 2006). Last decile-inflation, public debt, and credit to private sector. First decile-financial openness.
} 


\section{Panel $A$}

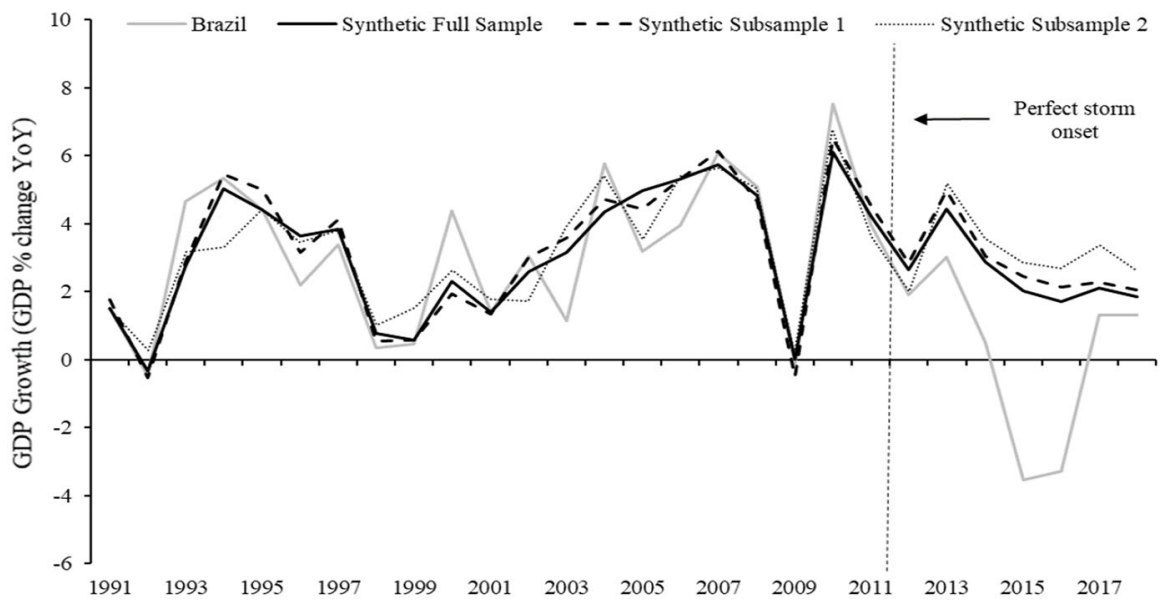

Panel B

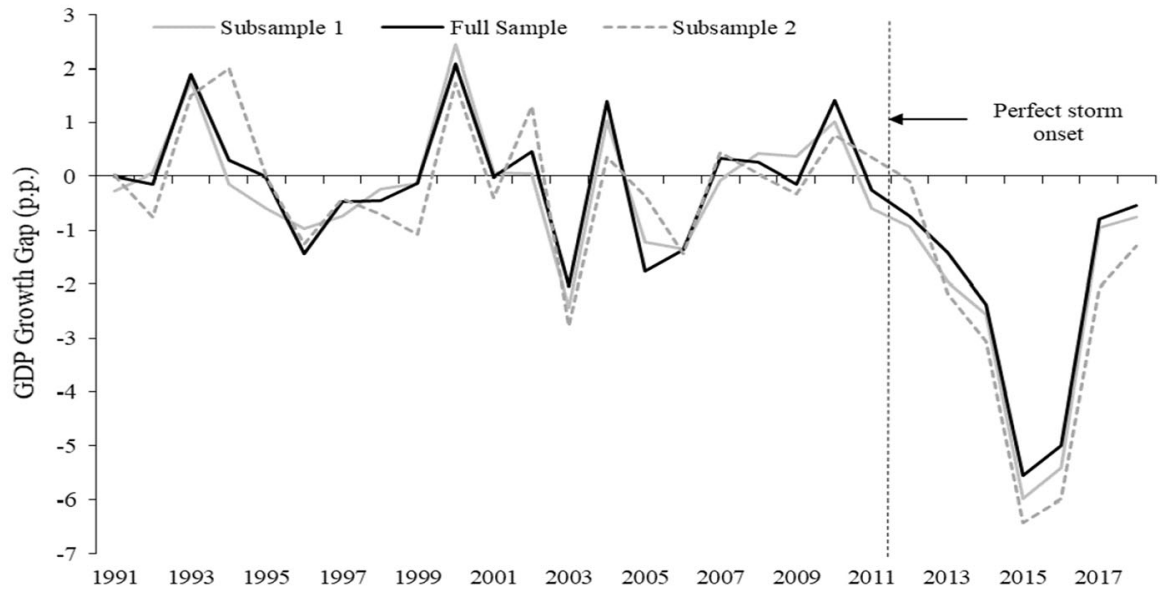

Fig. 7 Placebo test "donor pool subsample": synthetic and effect. Notes Panel A shows the trajectories of Brazil's economic growth, of synthetic Brazil (based on all 87 countries in the donor pool), synthetic Brazil built from the 27 upper-middle-income countries (subsample 1), and synthetic Brazil built from the 71 countries with an abnormal variation of key macroeconomic variables (subsample 2). Panel B shows the "perfect storm" effect on economic growth from the three samples under consideration

other words, even if we consider countries with an abnormal performance of the main macroeconomic variables in the sample, the "perfect storm" phenomenon remains.

\section{Complementary empirical analysis}

The analysis based on synthetic models in previous sections revealed that the "perfect storm" effect on the Brazilian economy was responsible for an economic growth rate 
lower than that found in other countries. However, we cannot rule out the relevance of the Great Recession of 2008-2009 and President Dilma Rousseff's impeachment to explain the drop in the growth rate. Therefore, to examine whether the effects caused by the Great Recession and impeachment are the only ones responsible for reducing growth, we carried out a complementary empirical analysis that considers the effects of the "perfect storm", the Great Recession of 2008-2009, and the impeachment on the growth rate. We analyzed this issue using quarterly time series in Brazil from 2004 to 2018 .

To consider the effects mentioned above, we used dummy variables in the model. In the case of the "perfect storm", the result from the synthetic control shows that the period 2011 (first quarter) to 2016 (last quarter) is the one in which the effect on growth is most remarkable. Therefore, the "Perfect Storm" variable assumes a value equal to " 1 " from 2011 to 2016 and zero for the other periods. Concerning the Great Recession, in September 2007, central bank actions began in response to the financial crisis. For example, the Bank of England provided financial support to the Northern Rock bank. The Federal Reserve Bank initiated a federal funds rate reduction process in response to concerns about liquidity and confidence (see O'Connell 2017; Andrews and Peters 2007). In January 2010, US President Barack Obama declared that the markets had stabilized (see US Department of the Treasury, 2010). Hence, the "Great Recession" variable, which captures the period in which the effect of the global financial crisis on the economy was most intense, assumes a value of " 1 " from the fourth quarter of 2007 until the last quarter of 2009, and zero for the others periods. Regarding President Dilma Rousseff's impeachment, the process started on December 2, 2015, with the acceptance by the President of the Chamber of Deputies of a complaint about a crime of responsibility that culminated in the termination of the mandate on August 31, 2016 (see Agência Brasil, 2015; BBC 2016). Consequently, the "Impeachment" variable assumes a value equal to " 1 " in the first two quarters of 2016 and zero for the others.

Therefore, the baseline model corresponds to:

$$
\text { GDP growth }_{t}=a_{0}+a_{1} \text { GDP growth }_{t-1}+a_{2} \text { Perfect Storm }_{t}+a_{3} X_{t}+\varepsilon_{t},
$$

onde: $X$ is a vector of control variables Great Recession and Impeachment, and $\varepsilon_{t} \sim$ $N\left(0, \sigma^{2}\right)$.

We show empirical evidence using Ordinary Least Squares (OLS) and the Generalized Method of Moments (GMM). The application of these methods is useful because it allows us to observe straightforward the coefficients and statistical significance of the variables of interest. We use GMM to control the bias of variables omitted from the models and the simultaneity risk between economic growth and the variables of interest. Furthermore, to address possible problems related to autocorrelation and heteroscedasticity in the models' error terms, we applied the Newey-West matrix to the OLS and GMM models' regressions. Because we are not using a large sample (60 observations), there is a possibility that GMM estimates are subject to small sample bias (see Hall 2005). Thus, we present the complete model result through a two-stage GMM regression using the Windmeijer matrix (2005). Moreover, to avoid excessive quantities of instruments in the models that could bias the results, we limit each model's 
maximum instruments to $1 / 3$ of the total sample. Finally, it is noteworthy that we use external instruments related to variables that can affect growth in an economy with Brazil's characteristics. ${ }^{15}$

Table 4 shows that OLS and GMM regressions result unequivocally show the negative effect on economic growth due to the "perfect storm". The Perfect Storm coefficient is negative and has statistical significance in all models. The inclusion of the variables Great Recession and Impeachment in the models show that the global financial crisis of 2008-2009, as well as the political instability caused by President Dilma Rousseff's impeachment, were also important to explain the poor performance of economic growth (both variables have coefficients negative and significant). The results of the Durbin-Wu-Hausman and $J$-statistic tests (columns 5 and 6) indicate that the variables considered in the models are exogenous to growth and that the adjusted model, as well as the instruments used, are adequate. In summary, there is evidence that even considering the shocks that marked the period under analysis, the combination of type 1 and type 2 economic policies worsened the deterioration in growth.

\section{Conclusion}

The use of economic policy and economic growth is one of the primary researches subjects in economics. The Great Recession of 2008-2009 forced policymakers to implement policies to smooth the downturn in economic activity. Brazil also followed this perspective; however, how the measures to combat the recession were implemented differed from those adopted in most countries. In particular, adopting inappropriate economic policies raised a "perfect storm" that resulted in an unprecedented drop in economic growth in twenty-first century Brazil. Hence, analyzing and pointing out what measures were detrimental to growth is vital to policymakers in other countries not to make the same mistakes and thus cause unnecessary social costs.

This article shows that the combination of economic policies that neglect the relevance of fiscal balance and the search for low and stable inflation, with those to stimulate economic growth without considering the side effects on the economy, led to a deterioration in the Brazilian economic growth. That could have been avoided if such measures had not been adopted. We carefully built a control unit that simulates Brazil's economic growth trajectory without the "perfect storm" to analyze this issue. The control unit, synthetic Brazil, can accurately reproduce the Brazilian economy's growth rate for the 20 years of the pre-treatment period. The findings show that the "perfect storm" reduced the economic growth by approximately $2.08 \mathrm{pp}$ in the posttreatment period. Moreover, the most significant effect occurred in 2015, with a drop of $-5.6 \mathrm{pp}$. It is noteworthy that the results found are robust to several placebo tests ("in-space", "leave-one-out", and use of a subsample of the donor pool). Furthermore,

\footnotetext{
15 Concerning the instruments, we use the iron and oil prices because in emerging and developing economies, these variables are relevant to explain economic growth (see McGregor 2017). Besides, we have included leading indicators of economic activity, such as changes in the Brazilian stock market index and business confidence. The exchange rate (R\$/US\$) captures the influence of financial flows and the international environment. Finally, we consider the public debt/GDP ratio because of its relationship to growth (see Abubakar and Mamman 2020). The list of instruments in each model is in Table A.3 (appendix).
} 


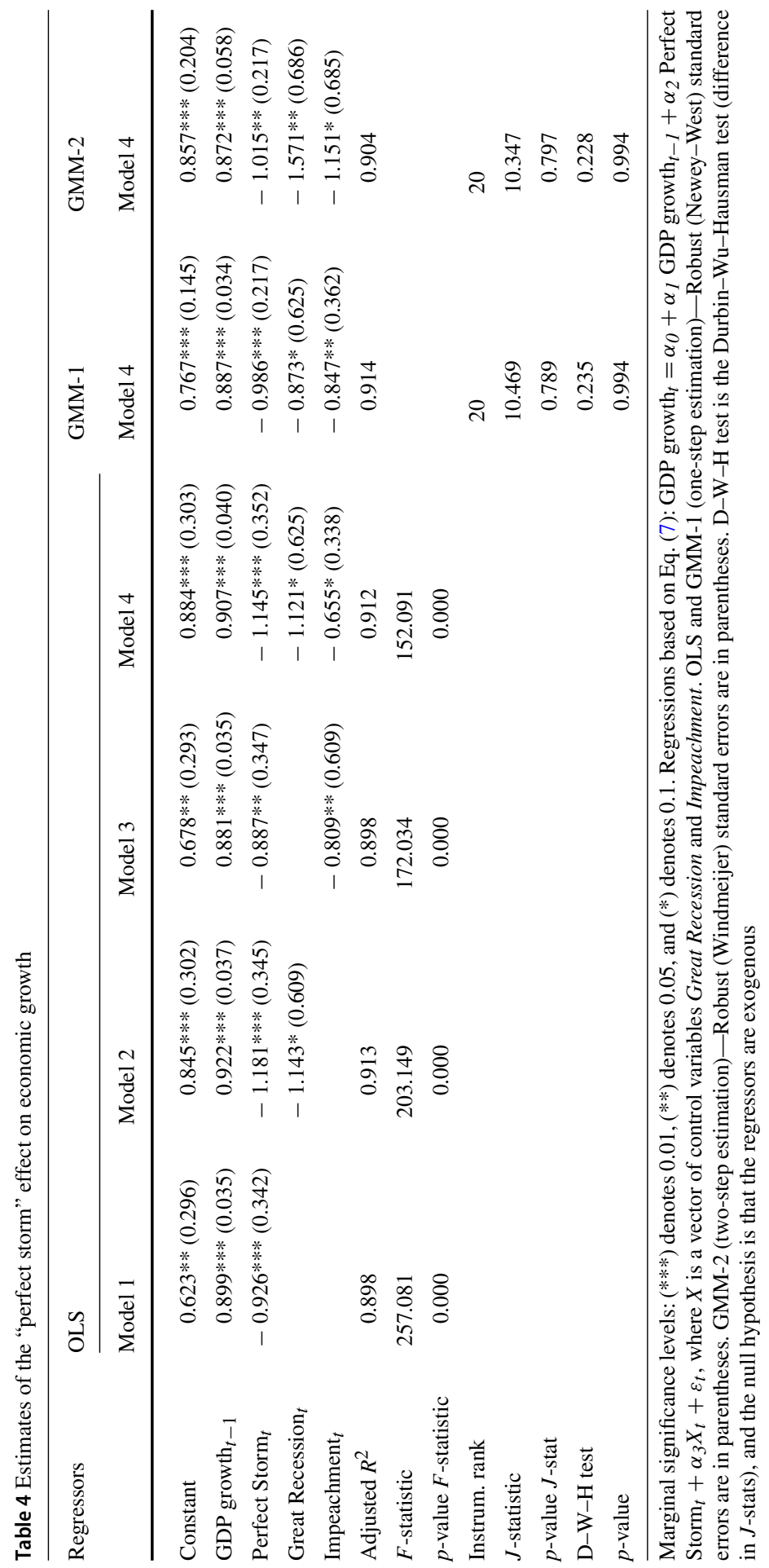


the result of the complementary empirical analysis, using OLS and GMM models, shows that the negative effect of the "perfect storm" is not eliminated even with the explicit inclusion of the great shocks in the period (Great Recession of 2008-2009 and President Dilma Rousseff's impeachment).

The results obtained have relevant implications for the management of economic policies in times of economic crisis. For example, the drop in economic activity due to the COVID-19 pandemic has led to a sharp drop in economic growth worldwide. As in the Great Recession of 2008-2009, all countries have sought to use measures to mitigate the decrease in economic growth. This observation is one of the merits of this study. Undoubtedly, countercyclical policies are useful; however, the inappropriate combination of measures can lead to a worse situation than letting the economy recover by itself.

Supplementary Information The online version contains supplementary material available at https://doi. org/10.1007/s00181-021-02167-4.

Funding Author Helder Ferreira de Mendonça has received research grants from the National Council for Scientific and Technological Development (CNPq-Brazil).

\section{Declarations}

Conflict of interest The authors declare that they have no conflict of interest.

Human rights This article does not contain any studies with human participants or animals performed by any of the authors.

\section{References}

Abadie A, Diamond A, Hainmueller J (2010) Synthetic control methods for comparative case studies: estimating the effect of California tobacco control program. J Am Stat Assoc 105(490):493-505

Abadie A, Diamond A, Hainmueller J (2011) SYNTH: stata module to implement synthetic control methods for comparative case studies. Stat Softw Compon S457334

Abadie A, Diamond A, Hainmueller J (2015) Comparative politics and the synthetic control method. Am J Polit Sci 59(2):495-510

Abo-Zaid S, Tuzemen D (2012) Inflation targeting: a three-decade perspective. J Policy Model 34(5):621-645

Abubakar AB, Mamman SO (2020) Permanent and transitory effect of public debt on economic growth. J Econ Stud (forthcoming)

Agência Brasil (2015) Eduardo Cunha accepts charges filed for Rousseff's ouster. Agência Brasil, December. https://agenciabrasil.ebc.com.br/en/politica/noticia/2015-12/eduardo-cunhaaccepts-charges-filed-rousseffs-ouster

Andrews EL, Peters JW (2007) Markets soar after fed cuts key rate by a half point. The New York Times, September. https://www.nytimes.com/2007/09/18/business/18cnd-fed.html

Arin KP, Braunfels E, Doppelhofer G (2019) Revisiting the growth effects of fiscal policy: a Bayesian model averaging approach. J Macroecon 62(C):103158

Attinasi MG, Klemm A (2016) The growth impact of discretionary fiscal policy measures. J Macroecon 49:265-279

Baharumshah AZ, Soon SV, Lau E (2017) Fiscal sustainability in an emerging market economy: when does public debt turn bad? J Policy Model 39(1):99-113

Barro RJ (2003) Determinants of economic growth in a panel of countries. Ann Econ Finance 4(2):231-274 
BBC (2016) Brazil President Dilma Rousseff removed from office by Senate. BBC News, September. https://www.bbc.com/news/world-latin-america-37237513

Bó ED, Bó PD, Eyster E (2018) The demand for bad policy when voters underappreciate equilibrium effects. Rev Econ Stud 85(2):964-998

Bogdanski J, Tombini AA, Werlang SR (2000) Implementing inflation targeting in Brazil. Working paper series, 1. Central Bank of Brazil.

Bussière M, Fratzscher M (2008) Financial openness and growth: short-run gain, long-run pain? Rev Int Econ 16(1):69-95

Carvalho C, Masini R, Medeiros MC (2018) ArCo: AN artificial counterfactual approach for highdimensional panel time-series data. J Econ 207(2):352-380

Chamon M, Garcia M, Souza L (2017) FX interventions in Brazil: a synthetic control approach. J Int Econ 108:157-168

Chinn MD, Ito H (2006) What matters for financial development? Capital controls, institutions, and interactions. J Dev Econ 81(1):163-192

de Guimarães e Souza GJ, de Mendonça HF, Andrade J (2016) Inflation targeting on output growth: a pulse dummy analysis of dynamic macroeconomic panel data. Econ Syst 40(1):145-169

de Mendonça HF, de Guimarães e Souza GJ (2012) Is inflation targeting a good remedy to control inflation? J Dev Econ 98(2):178-191

Galiani S, Quistorff B (2017) The synth runner package: utilities to automate synthetic control estimation using synth. Stata J 17(4):834-849

Hall AR (2005) Generalized method of moments. Oxford University Press, Oxford

Hartmann M, Roestel J (2013) Inflation, output and uncertainty in the era of inflation targeting-a multieconomy view on causal linkages. J Int Money Finance 37:98-112

Hendry DF, Krolzig HM (2004) We ran one regression. Oxf Bull Econ Stat 66(5):799-810

Hoover KD, Perez SJ (2004) Truth and robustness in cross-country growth regressions. Oxf Bull Econ Stat 66(5):765-798

IMF (2011) Annual report on exchange arrangements and exchange restrictions

Lombardi D, Siklos P, Amand S (2018) A survey of the international evidence and lessons learned about unconventional monetary policies: is a "new normal" in our future? J Econ Surv 32(5):1229-1256

McGregor T (2017) Commodity price shocks, growth and structural transformation in low-income countries. Q Rev Econ Finance 65:285-303

McManus R, Ozkan FG (2015) On the consequences of pro-cyclical fiscal policy. Fiscal Stud 36(1):29-50

Mishkin FS (2000) Inflation targeting in emerging-market countries. Am Econ Rev 90(2):105-109

Mollick AV, Cabral R, Carneiro FG (2011) Does inflation targeting matter for output growth? Evidence from industrial and emerging economies. J Policy Model 33(4):537-551

O’Connell D (2017) The collapse of Northern Rock: ten years on. BBC News, September. https://www. bbc.com/news/business-41229513

Samarina A, Terpstra M, de Haan J (2014) Inflation targeting and inflation performance: a comparative analysis. Appl Econ 46(1):41-56

Stone JA (2016) Do balanced-budget rules increase growth? Bull Econ Res 68(1):79-89

Tarek BA, Ahmed Z (2017) Governance and public debt accumulation: quantitative analysis in MENA countries. Econ Anal Policy 56:1-13

Tiffin R, Irz X (2006) Is agriculture the engine of growth? Agric Econ 35(1):79-89

Twinoburyo EN, Odhiambo NM (2018) Monetary policy and economic growth: a review of international literature. J Cent Bank Theory Pract 7(2):123-137

Windmeijer F (2005) A finite sample correction for the variance of linear efficient two-step GMM estimators. J Econ 126(1):25-51

Wong KM, Chong TTL (2019) Monetary policy regimes and growth revisited: evidence from a de facto classification. Oxf Econ Pap 71(4):908-929

Xue W, Yilmazkuday H, Taylor JE (2020) The impact of China's fiscal and monetary policy responses to the great recession: an analysis of firm-level Chinese data. J Int Money Finance 101:102113

Publisher's Note Springer Nature remains neutral with regard to jurisdictional claims in published maps and institutional affiliations. 